\title{
국제개발협력의 역사적 배경과 그 시사점 대아프리카 대륙을 중심으로
}

- 인식론적 관점에서 본 국제개발협력-

조 원 호 (前 KOICA 이사 한국외국어대학교 국제지역대학원 석좌교수)

\section{목 차}

I . 머리말

II. 개발에 대한 서구의 인식 체계 변화

1. 자연과 신으로부터 이성과 인간에 의한 개발

2. 식민제국주의에 의한 고급문명이라는 개발

3. 정신적 문명에서 물질적 개발원조로

III. 아프리카의 인식체계

1. 헤겔과 아프리카

2. 아프리카 지식층에 나타난 인식체계

3. 이성으로 진화한 지배계층과 신화속에 갇힌 국민

$\mathrm{IV}$. 서구와 아프리카 간 인식체계의 차이가 개발협력에 주는 시사점

1. 서구의 단선적이고 우월적 개발협력

2. 아프리카의 인식구조

$\mathrm{V}$. 맺는 말 


\section{I . 머리말}

“아프리카 대륙이 아프리카 본래의 전통과 문화 그리고 이성을 되찾으면 아프리카는 다시 부흥할 수 있어요. 아프리카의 고대 문화와 문명은 유럽보다 앞서있었지요. 서구가 발전한 것 은 17 세기 이후 의식혁명과 산업혁명의 결과일 뿐이예요. 서구는 식민제국주의를 통하여 아프 리카의 문화와 역사를 파괴하고 이성과 철학을 왜곡시키면서 아프리카에 대한 인식을 서구위 주로 조장하였어요. 이성과 합리성은 상대적인 개념 뿐이예요.” 한국국제협력단(KOICA)이 2011년부터 주관하여 실시중인 장기석사과정에 참가한 아프리카지역 공무원들이 서구에 대한 자신들의 소견을 위와 같이 밝혔다. ${ }^{1)}$ 연수공무원들은 서구의 인식체계로 국제개발협력을 추 진할 경우 개발협력의 효과는 나타나지 않을 것이라고 강조하였다. 또한, 세계은행 등 국제개 발기구들이 새천년 개발 목표(MDG)를 아프리카의 실상을 고려하지 않고 정량분석방법으로 수치 달성에 목적을 두고 있기 때문에 달성되어도 의미가 없다고 생각한다.

독일의 철학자 헤겔은 아프리카를 이해하기 위해서 서구의 인식체계를 버려야 한다고 간파 하였다. 헤겔은 아프리카인들은 이성(reason)이 없기 때문에 생각할 줄 모르고 그 때문에 역 사도 없고 문화도 없다고 기술하였다. 그는 아프리카인을 비상한 기억력으로 남의 말을 따라 할 줄은 알아도, 이성과 지성에 의한 인식 능력이 없고 혁신적인 정신이 모자라 진화할 수 없 고 발전할 수 없다고 보았다. 헤겔은 아프리카에 대한 부정적 인식은 아프리카의 지식인과 정 치인들에게 커다란 반항을 일으켰다. 그러나 아프리카인들은 진화할 수 없는 인종이라는 헤겔 의 생각은 서구의 인식 체계에 이미 각인되어 있었다. 프랑스의 철학자 볼테르나 독일의 철학 자 헤르더(Herder) 등도 아프리카인을 동물에 비유할 정도로 극언하였다.

진화(evolution)라는 용어를 처음으로 자연계와 사람에게 적용한 사람은 18 세기 중엽의 보 네트(Bonnet)였다. 이를 진화론이라는 틀로 초안을 잡은 사람은 뷔퐁(Buffon)이였고 학문적 으로 체계화시킨 사람이 라마르크(Lamarck)였다. 뷔퐁은 백인만이 진화과정을 완성하여 최고 의 문명수준에 달한 인종이기 때문에, 백인은 다른 미개인종을 문명화시킬 의무가 있다고 주 장하였다. 인종(race)이라는 단어는 원래 귀족의 가계나 혈통을 증명하는데 사용되었다. 근대 적 의미에서 인종이라는 용어는 프랑스의 물리학자인 베르니에(Bernier)에 의하여 처음으로 학문적으로 소개되면서 다양하게 정의되었다. 스웨덴의 생물학자였던 리나에우스(Linnaeus)

1) 상기 석사과정은 한국외국어대학교 국제지역대학원에서 실시중이다. 아프리카 지역 공무원과 우리나라가 현장에서 함께 호흡하기 위하여 우리나라 교수들이 프랑스어로 강의한다. 
는 인종을 백인, 홍인, 황인, 흑인으로 구분하고 백인과 흑인을 도덕적 차원에서 비교하였다. 특히, 프랑스 귀족출신의 외교관으로서 나치즘에 영향을 준 고비노(Arthur de Gobineau)는 인종적 불평등에 관한 에세이(An Essay on the Inequality of the Human Races)를 통하여 인류를 백인종, 황인종, 흑인종으로 구분하고 백인만이 탁월한 우수성을 지니고 있기 때문에, 백인만이 최고의 문명수준에 도달할 수 있다고 주장하였다.

이와 같은 유럽의 인식체계에 대하여 연수 공무원들은 다음과 같은 문제를 제기했다. "노예 무역으로 아프리카 인들을 고통으로 몰아놓고 착취한 것이 이성이고 합리성인가? 아프리카 대 륙을 유럽의 취향에 맞게 나누어 인종 간 불화를 조장시키고 그 와중에 이권을 챙기는 유럽의 행태가 이성적이고 합리적인가? 두 차례의 세계대전을 일으켜 수많은 사람을 희생시킨 것이 이성에 의한 진화인가?” 연수공무원들은 최근에 서구가 쇠퇴의 기미를 보이는 반면 중국이 부 상하듯이 아프리카대륙도 다시 일어날 것을 확신하였다. 그들은 서구의 이성에 의한 합리주의 나 관념론을 서구관점에서의 이성이고 철학일 뿐이며 아프리카는 고유의 이성과 철학으로 고 유의 인식체계를 갖고 있다고 밝혔다.

근대이후의 서구의 인식체계는 이성과 합리성 그리고 과학에 근거를 두면서 진화해왔다. 서 구는 서구의 문명이나 생활수준에 미치지 못한 국가를 야만국가 또는 저개발국가로 분류하고 이들 국가를 가르치고 도와주어야 한다는 명분을 내세워왔다. 그러나, 서구는 아프리카대륙을 진화과정에서 가장 뒤떨어진 지역으로 비하시키면서, 아프리카의 지식인들로부터 강한 반발을 불러일으켰다. 아프리카 지식인들은 서구의 이성과 합리성을 편향된 이기적 발상이라고 보았 다. 역사학자 쉐이크 디오프(C.A. Diop)등 일부지식인들은 사적자료를 근거로 아프리카가 오 히려 문명의 요람이며 서구의 문명에 영향을 주었다고 주장하였다. 세네갈의 작가였던 알리운 디오프(A. Diop)는 서구중심의 이성으로는 진정한 보편주의에 도달할 수 없으며, 미래의 세계 는 모든 인류가 함께 만들어 가야 한다고 천명하였다. 그는 아프리카가 세계역사를 만들어 가 는데 참가(Présence)해야 한다는 목적의식을 갖고 1947년 Présence Africanie 잡지를 창간하 였다.

그러나 아프리카 권력 엘리트들이 자본주의도 공산주의도 아닌 제 3 의 길을 표방하고 나서 면서, 아프리카는 이해하기 어려운 이상야릇한 신화의 대륙이 되었다. 아프리카의 지도층의 담론, 지식층의 이데올로기와 국민들의 생활상등을 종합 관찰해볼 때, 아프리카의 인식체계는 흑인의 정신적 전통유산인 네그리뒤뜨(négritude), 흑인의 정체성을 나타내는 오땅띠씨떼 (authenticité), 그리고 흑인의 결속을 다지는 쏠리다리떼(solidarité)로 특징지을 수 있겠다. 
한마디로, 서구가 이성과 과학에 기초한 합리주의라면, 아프리카는 감성과 자연에 기초한 신 비주의다.

연수 공무원들은 가난이라는 현실 때문에 어쩔 수 없이 원조를 받지만, 서구 원조공여국은 싫어한다고 실토하였다. 개발원조의 효과제고를 위하여 각종 청사진을 내놓았지만, 청사진을 보는 시각은 서구와 다르다. 이런 상황에서 아프리카대륙에서 국제개발협력의 효과를 기대하 는 것은 무리다.

본고에서는 우선 서구의 문명과 문화를 비서구권에 전파하려는 서구의 의식체계를 역사적 과정을 통하여 살펴본다. 다음으로, 서구 중심의 인식체계에 대한 아프리카의 반응을 문화와 이성(철학)적 측면에서 고찰한다. 아울러, 아프리카 엘리트층이 만든 신화의 내용을 알아본다. 끝으로 양진영간의 의식체계의 차이가 국제개발협력에 시사하는 본질적 의미를 음미해본다.

\section{II. 개발협력에 대한 서구의 의식체계}

\section{1. 자연과 신으로부터 이성과 인간에 의한 개발}

생물학과 자연 현상에 관심이 많았던 철학자 아리스토텔레스는 일찍이 세상의 모든 생명체 는 목적을 향하여 변화한다고 보았다. 아리스토텔레스는 과학과 역사를 구분하였다. 과학은 필연에 의하여 나타날 수밖에 없는 현상이지만, 역사는 우연적으로 나타나는 사건 정도로 생 각하였다. 아리스토텔레스는 자연의 변화를 과학의 필연성으로 간주하였다. 우리에게 산천이 라는 자연은 의구한 것으로 익숙하지만 아리스토텔레스에게는 자연은 필연적으로 도달해야할 목표를 향하여 움직이는 원천을 갖고 있다고 보았다. 움직이는 원천이 있다는 사실을 생성하 고 성장하여 어느 목표를 향하고 있다는 의미다. 아리스토텔레스는 이와같이 움직이는 현상을 개발(development)이라고 생각하였다. 그러나, 아리스토텔레스는 생명체가 무한정 성장하는 것이 아니라 순환한다고 보았다. 즉, 태어나서 성장하고 노쇠하면 죽는다는 순환 과정이 끊임 없이 지속된다고 생각했다.

반면, 신학자 아우구스티누스는 생사의 과정은 거치되 반복되지는 않는다고 보았다. 그는 
인류역사의 시작과 끝이라는 신의 계획에 따라 전개될 뿐이라고 생각하고 아리스토텔레스의 반복순환을 부정하였다. 이 때문에 4 5세기에는 최후의 심판이나 지구 종말론이 인구에 회자 되었다. 아우구스티누스의 역사철학은 인류의 구원(salvation)을 근본으로 하였다. 어느 특정 지역이나 시대에 초점을 두었던 여타 철학자와는 달리 아우구스티누스는 범 세계 (universality)를 대상으로 하고, 이 범 세계는 신의 섭리에 따른다고 보았다. 이러한 아우구 스티누스의 철학은 중세기 내내 커다란 반향을 일으켰다. 로마제국이 멸망하면서 세계는 신의 계획에 따라 종말을 고할 것이라는 생각을 갖게 되었다. 이런 가운데, "우리는 거인의 어깨 위 에 앉아있는 난쟁이”라는 버나르 드 샤르트르(Bernard de Chartres)의 금언에 따라, 지식은 축적되지만 옛 선조의 지식은 초월할 수 없다는 생각이 팽배하였다. 고대를 다시 찾겠다는 르 네상스(문예부흥)의 시작을 알린 것이다.

17세기 초까지 인간의 지식과 이성에는 한계가 있기 때문에 인간의 이성과 지식에 전적으로 의존하지 말아야 한다는 인식이 지배적이었다. 이런 가운데 데카르트를 중심으로 한 합리론자 들은 역사가 신의 계획에 따라 전개되고 고대인이 현재보다 지식수준이 높다는 생각을 부인하 고 나섰다. 데카르트는 인간은 이성(rationale)에 의하여 자신의 운명을 이해하고 또 만들어 갈 수 있다고 밝힘으로서, 인간의 발전(progress)이라는 개념의 초석을 다져 놓았다. 그는 인 류를 포함한 만물은 초인간적 운명의 힘의 지배 받는다는 믿음을 파괴시켰다. 세상의 참된 보 편적 진리는 하나밖에 없다고 보았다. 데카르트에게는 나(I)라는 자율적 주체의 존재만이 참된 보편적 진리다. 이성적이고 합리적인 진리, 즉 내가 아닌 진리는 이성의 발전에 방해되며, 이 러한 비이성적(irrationale) 진리는 존재할 이유가 없다고 보았다. 데카르트는 전통과 권위가 이성적이 아니기 때문에 전통과 권위에게 가치를 부여해서는 안된다고 지적하였다. 문화도 비 이성적인 전통과 권위에 기반을 두고 있기 때문에 문화도 배척해야 한다고 보았다. 즉, 그는 영혼이 없는 모든 존재의 진실성을 인정하지 않았다. 특히, 인간은 인식론적 차원에서 이성을 통하여 자연을 이해하고, 윤리적 차원에서 자연을 정복 및 조정하고, 목적론적 차원에서 세계 를 재구성한다는 논리를 폈다. ${ }^{2)}$ 데카르트의 이러한 인식론과 목적론은 당시 사조와 정반대되 는 발상이었다.

인간은 이성에 의하여 발전한다는 데카르트의 생각은 18 세기 계몽주의의 기초가 되었고 19 세기 근대화 추진의 시발점이 되었다. 퐁트넬(Fontenelle)도 고대가 현대보다 높은 지식수준

2) Luuk Knippenberg and Francs Schuurman, stripped: A Critical Phenomenology of Press and Development, in Gabriele Koholer et als(eds). Questioning Development, Essays on the theory, policies and practice of development interventions, Metropolis-Verlag Marbug 1996, pp 45-70. 
을 보유한 것이 아니라 현대가 고대보다 높은 수준의 지식을 갖고 있다고 주장하고 합리론을 옹호하였다. 퐁트넬은 거인 위에 난장이가 있기 때문에 거인보다 난장이가 높은 위치에 있듯 이 고대를 기반으로 현대가 위치하기 때문에 현대가 고대보다 높은 지식을 갖고 있다는 논리 를 폈다. 퐁트넬은 인류를 이성(raison)의 발달 수준에 따라 인류의 발달과정을 설명하였다. 퐁트넬은 인류가 태고에 태어나서 상상하고 시를 지으며 유년기를 보내고, 청소년기에는 이성 으로 이치를 깨닫기 시작하였으며, 이제(17세기) 장년기를 맞으면서 과거의 어느 때보다 명철 하게 이성과 지식으로 판단하는 단계에 와있다고 주장하였다. 나아가, 퐁트넬은 인류는 늙는 다고 퇴보하는 것이 아니라고 생각하였다. 3) 라이프니쯔도 발전이 중지하고 퇴보하는 것처럼 보이는 것은 단지 외견상일 뿐이라고 지적하고 이성으로 끊임없이 발전할 수 있다고 보았다.4)

반면에, 루소는 발전(progress)은 우리의 죄악과 허영에 찬 호기심의 결과라고 주장하였다. 흄(D. Hume)5) 같은 철학자도 루소와 같이 발전에 대하여 회의적이었다. 이에 대하여 자연 박 물학자인 뷔퐁(G. Buffon)은 자연의 역사를 예로 들어 루소를 반박하였다. 뷔퐁은 모든 생물 의 종(種)에 가장 모범이 되는 전형(典型, prototype)이 있다고 주장하면서, 인류 과정에서 백 인만이 완성된 인종이라고 보았다. 나아가 뷔퐁은 유럽인은 최고수준의 문명에 도달했기 때문 에, 유럽은 다른 미개세계를 문명화시킬 책임이 있다고 주장하였다.6)

같은 시대의 철학자 콩도르세(Condorcet)는 인간정신의 발전에 관한 역사적 묘사라는 책을 통하여, 자연과 사회과학에 관한 지식의 확대가 개인의 자유, 물질적 풍요, 그리고 도덕적 연 민(moral compassion)을 유발한다고 주장하였다. 특히 콩도르세는 인류가 존재하는 한 지속 적으로 발전하며, 인류는 유토피아 같은 사회를 갈망하고 있다고 주장하였다. 또한, 축적된 지 식을 통하여 누구나 자연세계를 이해할 수 있다고 보았다. 콩도르세의 발전에 대한 인간 정신 (Progrès de l'esprit humain)은 프랑스의 계몽주의 사상에 큰 몫을 차지하였다. 콩도르세는 인류의 역사를 열 단계로 구분하고 마지막 단계에서는 국가 간 불평등이 사라지고 인류가 완 성단계에 도달한다고 보았다. 그는 유럽은 식민지 국가들의 독립을 존중할 것이고 식민지 국

3) Bernard Le Bovier de Fontenelle, Poésies pastorales avec un Traité la nature de l'égloque et une Digression sur les Anciens Poltes et Modernes, La Haye, Louis Van Dole et Estienne Foulque, 1688. p227-228

4) Gottfired Wilhelm Leibniz, La naissance du calcul différentiel, introduction et notes par M. Parmentier, Paris, Vrin, 1959. P51, note 139

5) Jean-Jaques Rousseau, Du contrat social. Discours sur les sciences et les arts. Discours sur l'origne de l'inégalité parmi les hommes, Paris, Union générale d'éditions, 1973.

6) Michéle Duchet, Anthropologie et histoire au Siècle des lumiロres. Buffon, Voltaire, Rousseau, Helvétius, Diderot, Flammarion, 1977, p35. 
가들이 독립하면 이들 국가들은 복지와 문명화를 위하여 유럽으로부터 재정적 도움(moyens) 을 요청할 것이라고 내다보았다. ${ }^{7)}$ 계몽주의의 이데올로기에 개발협력(원조)이라는 씨앗을 심 은 것이다.

\section{2. 식민제국주의에 의한 문명이라는 개발}

18-19세기 유럽의 사상적 조류였던 자유주의의 사상가들은 식민지를 문명화시켜야 한다는 사명을 인정하고 지지하였다. 식민주의의 정당성을 이론화한 최초의 자유주의자는 존 로크였 다. 로크는 영국의 아메리카인들에 대한 식민화는 원주민을 문명화시키는 필요하고 정당한 것 이라고 보았다. 특히, 로크는 영국의 식민화는 신과 인류 그리고 원주민에게 도덕적으로 봉사 하는 행위로 간주하였다. 아울러 신은 인간이 번영하기를 원하기 때문에, 인간은 자원을 개발 하여 생활을 향상시킬 의무가 있다고 생각하였다. 그리고, 이러한 생활을 영위하지 못하는 미 개국(인디언)을 문명세계로 인도해야한다고 주장하였다.8) 자유주의 사상가인 존 스튜어트 밀 도 인간사회를 문명화된 사회와 후진 사회로 구분하고 로크와 생각을 같이 하였다. 이들 자유 주의 사상가들은 서구의 이성적이고 목적 있는 삶만이 인간의 가치있는 삶으로 간주하였다. 그리고, 서구는 이를 문명화되지 못한 국가에 전파할 사명이 있다고 주장하였다. 제국주의의 정당성을 도덕적 가치관에서 찾은 것이다.

이러한 서구 중심주의 내지 우월주의는 서구사회 내에서 보편화 되면서 본격화되었다. 세이 (Say)는 인류는 야만단계를 거쳐 저급의 문명세계를 지난 후 고급의 문명사회에 도달하게 되 며, 야만사회는 제한된 필요(Besoins limités)를 충족시키는데 비하여, 고급 문명사회는 산업 발전을 통하여 인류의 폭넓은 필요(Grande variété de besoins)를 충족시키게 된다고 밝혔 다. 1970 년대의 개발목표였던 인간의 기본적필요(basic human needs)를 이미 간파하였다. 세이는 문명과 산업의 힘을 무시한 민족은 생존하지 못한다고 보았다. ${ }^{9)}$ 콩트(Compte)는 인간 정신의 발달을 신학적(téologique) 단계에서 형이상적(métaphysique)단계를 거쳐 실증단계 (état positif)로 구분하였다. 그는 형이상적 단계에서는 이성이 신앙을 대신하지만 논리가 허

7) Marquis de Condorcet, Esquisse d'un tableau historique des progrロs de l'esprit humain, p328.

8) Bhikhu Parekh, The West and Its Others, in Cutural Readings of Imperialism : Edward Said and the Gravity of History, Keith Pearson, Benita Parry \& Judith Squires, eds., St. Martin's 1997, p180-183

9) Jean-Baptise Say, Cours complet d'Iconomie politique pratique, Bruxelles, Soci[t typographe belge, 1843. 
구적이며, 실증단계에서 비로소 인간은 경험적 사실에 근거한 과학의 덕으로 최고의 단계에 도달하게 된다고 주장했다. ${ }^{10)}$ 특히, 콩트는 발전을 질서(order)의 단순한 개발 (développement)과정으로 간주하고, 모든 자연의 질서는 필연적으로 자연 자체 내에 자기 순 서에 맞는 발전의 씨앗을 보유하고 있다고 보았다. 이런 맥락에서, 콩트는 학문을 수학, 천문 학, 물리학, 화학, 생물학, 사회학 순으로 배열하고, 이 순서에 따라 앞의 학문이 뒤의 학문을 뒷받침하게 된다고 주장하였다. 이런 논리에 따라, 콩트는 인류의 사회생활을 연구하는 사회 학도 화학이나 생물학 등 과학을 통하여 실증할 수 있다고 보았다. ${ }^{11)}$ 콩트는 신학이나 형이상 같은 추상적인 사변이 아니라 과학적인 방법으로 인간 사회를 설명하면서, 과학적 지식의 성 장이 인류 역사의 발전과 동일하다고 본 것이다. 콩트는 이러한 인류사회의 발전을 생물유기 체에 비유하고, 생물유기체의 질서와 발전의 논리를 인간 사회의 질서와 발전에 접목하여 설 명하였다. 이러한 콩트의 생각은 스펜서에게 큰 영향을 주었다.

스펜서는 콩트의 영향을 받아 사회라는 유기체가 진화하는 것을 생물체(living organisms) 에 비유하였다. 그의 사회유기체적 진화론은 19 세기 말엽을 전후 한 식민지 정책을 정당화하 는데 공헌하였다. 스펜서는 식물체가 동질의 상태(homogeneity)에서 이질의 상태(heterogeneity)로, 단순 생물체에서 고등 생물체로 진화한 것처럼 인류 사회도 낮은 단계에서 높은 단계로 진화한다고 생각하였다. 그는 발전은 유익하면서 필요한(beneficent necessity)것으로 보고, 농업 사회보다는 과학 기술을 기반으로 하는 서구 사회가 우월하다고 생각하였다. 또한, 인류도 동물들처럼 생존투쟁에 예속되어 있고 투쟁은 인류의 진보를 가져온다고 주장하였다. 그는 원시사회와 군사적 유형의 사회가 근대산업 유형의 사회로 바뀌면서 부족이나 종존 간의 생존투쟁에서 한 사회내부에서의 개인 간 생존투쟁으로 변화한다고 보았다. ${ }^{12)}$ 특히, 적자생존 (survival of the fittest)이라는 용어를 사용하여 경쟁에 이긴 사회조직만이 생존하면서 사회 수준을 향상시킨다고 생각하였다. ${ }^{13)}$ 이런 맥락에서, 스펜서는 가난한 사람을 도와주는 것을 반대하였다. 적자생존을 자연적인 진화로 간주하고 개인의 자유로운 창의성(intiative)을 억제 하는 모든 조치를 반대하고 자발적인 진화에 기초한 자유주의를 강조하였다. 그는 제국주의를 유럽의 하얀 야만인들이 도처의 검은 야만인을 유린하고 게걸스럽게 잡아먹는 것으로 묘사하 고, 제국주의에 의하여 인류문명은 야만적이 될 것이라고 지적하면서 제국주의를 반대하였다.

10) Auguste Compte, Syst $\square m e$ de politique positive ou Trait $\square$ de sociologie institutuant la religion de l'humanit口, 1854.

11) 콩트의 실증주의는 종교나 철학의 고유가치를 과학이라는 잣대로 해석하려는 편협한 사상으로 비판받아왔다.

12) Herbert Spencer, The Principles of Sociology vol.2, 1914

13) Herbert Spencer, A Theory of Population, Deduced from the General Law of Animal Fertility, The Development Hypothesis, 1852. 
한편, 스펜서와 시대를 같이한 다윈은 생물의 진화가 진보를 의미하는 것은 아니라고 하였다. 즉, 생존했다고 해서 이전의 단계보다 우수하다고 여기지 않았다. 다윈은 종의 기원(The Origin of Species)에서 자연의 다산성, 종의 변이, 생존경쟁, 자연선택(natural selection)의 내용을 담은 생물학적 진화론을 제시하였을 뿐이지 종의 우열을 지적한 것은 아니었다.

사회진화론은 19 세기 말 사라져가던 식민주의를 부활시키고 식민주의를 합법화하는데 단초 를 제공하였다. 당시 프랑스에서는 식민화에 대한 찬반 논쟁이 있었다. 식민화를 반대하는 진 영은 식민화가 자유무역에 어긋나고 노예제도는 인권에 반하기 때문에 반대한다고 나섰다. 루 소, 몽테스키외, 아담스미스, 세이 등은 자유 무역이 오히려 시장의 규모를 확대해주고 식민지 의 산업을 육성하는데 도움을 준다고 주장하면서 식민화에 의한 보호주의를 비난하였다. 콩도 르세와 미라보는 인권차원에서 노예제도를 반대하였다. 이런 가운데 프랑스는 1808년 노예제 도를 폐지하기로 결정하였으나 19 세기 말에 들어서면서 영국, 독일, 이태리, 벨기에가 식민정 책을 통하여 영토를 확장하면서 프랑스도 다시 식민화 정책을 강화하기 시작하였다. 군부와 무역상, 그리고 선교사들이 식민지 정책의 강화에 이바지하였다. 선교사나 반노예제도 주창자 들까지 식민화가 노예제도를 없애고 노예무역이 끼쳤던 피해를 복구하는데 도움을 주는 것으 로 여론을 이끌었다. 프랑스 문호 빅토르 위고는 19세기의 백인은 흑인을 인간으로 만들었고 20세기 유럽은 아프리카를 세계의 일원으로 만들 것이라고 말했다. 위고는 유럽의 문명으로 아프리카를 개조하기 위하여 아프리카를 점유하자고 제안했다. 그는 신은 지구를 인간에게 주 고 아프리카를 유럽에게 주었다고 말하면서 정복이 아니라 형제애로 전투가 아니라 산업을 위 하여 무력이 아니라 무역으로 아프리카를 차지(prenez-la)하자고 열변했다. ${ }^{14)}$ 19세기 말 프 랑스 훼리(J. Ferry) 총리는 국제 경쟁이 치열한 상황에서 생산의 지속적인 증가와 자본 축적 을 위해서는 새로운 시장이 필요하기 때문에 이를 위하여 경제영역을 넓혀야 한다고 주장하였 다. 그는 우등 인종은 열등 인종과 과학과 발전의 혜택을 공유할 의무와 권리가 있고 식민화는 열등 인종에게 빛(문명)과 질서, 그리고 덕을 가져다주며 노예무역과 노예제도라는 치욕에서 벗어나게 해준다고 역설하였다. 보리외(Beaulieu)는 근대화 국민에 의한 식민화라는 저서를 통하여 식민화는 최고의 문명 수준에 도달한 사회가 이제 막 태어난 새로운 사회의 성숙(발전) 을 도와주는 사회 심리적 현상이라고 언급하였다. 나아가, 보리외는 식민화의 장점은 미성숙 한 사회에게 발전하기에 적합한 조건을 만들어주고 성장에 필요하고 유익한 방법과 도구를 주 는 것이라고 언급하였다. ${ }^{15)}$ 결국, 식민화는 선택의 문제가 아니고 의무이며 기정 사실(fait

14) Jean-Marc Ela, Les Cultures Africaines Dans le champ de la Rationalité Scientifique, Livre II, L'Harmattan, 2007

15) Paul Leroy-Beaulieu, De la Colonisation chez les peuples modernes, 1874. 
accompli)로 낙착되었다.

식민화는 인류의 보편적 가치 향상을 위한 도덕적 의무이며 이러한 섭리를 피하는 것은 도 덕적 쇠락을 의미하였다. 식민화에 대한 비난은 인류의 운명에 무관심한 사악하고 배은망덕한 시민의 잘못된 이기적 행동으로 평가되었다. 인류애의 관점에서도 식민화는 식민지의 인권과 자유를 보장해주기 때문에 식민화를 지속하는 것이 의무이며 책임이라는 생각이 자리 잡게 되 었다. 이에 맞추어 서구는 인류애와 문명, 그리고 계몽이라는 명목 하에 시장개척과 천연자원 개발에 나섰다.

프랑스는 1889년에 식민지 국민의 교육을 위한 기관을 설립하였다. 오늘날 개도국공무원 연 수 프로그램의 시조라 할 수 있다. 또한, 식민지 문화를 고려하여 현지 특성에 맞는 정치, 경 제, 법적 제도를 수립 하였다. 아울러, 위생시설도 세웠다. 유럽식 교육제도를 이식하고 문제 가 발생하면서 어느정도 현지에 적합한 교육과정(예: 농사실습)을 시행하였다. 마을 단위의 은 행이나 여성의 지위, 주민 참여 등도 고려되었다. 그러나 그것은 당의정이었다. 식민지 국민에 대한 강제 노동과 부역, 강제 이주, 환금작물 플란테이션 등으로 전통경제문화와 사회 관습을 파괴하였다.

유럽은 식민지가 성숙단계에 들어서면 독립(emancipation)할 것이라는 명분으로 식민화를 추진하였다. 프랑스 경제학자 튀르고는 식민지를 과일에 비유하여 과일이 익을 때까지만 식민 화한다고 언급하였다. 그러나 유럽은 식민지보다 과학이나 도덕면에서 수세기 앞서 있다는 이 유로 식민지의 독립을 끝까지 미루었다. 사로(Sarraut)는 프랑스가 과학과 경험 그리고 도덕 측면에서 수세기 뒤떨어진 민족을 보호하고 지도할 유산(patrimoine)을 부여받았기 때문에 식 민화를 끓임없이 지속해야 한다고 주장하였다. ${ }^{16)}$ 결과적으로, 합법성과 타당성으로 시작된 식 민화는 식민지와 본토 간 비대칭적이고 불평등한 상하관계를 설정하였다.

\section{3. 정신적 문화에서 물질적 개발원조로}

세계 1 차 대전 후 국제연맹은 유럽의 식민정책이라는 유산을 국제적으로 승계시켰다. 국제 연맹규약 22 조는 소위 유럽 문명국의 식민 통치 이념을 그대로 이어받아 자신의 힘으로 일어 설 수 없는 국가의 복지와 발전을 위하여 문명이라는 성스러운 사명(mission sacrée)이 필요 16) Albert Sarraut, La mis en valeur des colonies francaises, Paris, Payot, 1923, 656. 
하다고 규정하였다. 또한, 발전의 수준(stage of development)에 따라 신탁통치를 받는다고 명시하였다. 식민지의 발전의 정도에 따라 문명이라는 신성한 척도로 식민지를 계속 보호하고 지도하자는 국제연맹의 정신은 계몽주의 사상과 사회진화론의 기조를 그대로 이어받았다. 다 만, 식민지를 보호하고 지도한다는 유산이 식민통치국이라는 특정 국가에서 국제 연맹이라는 국제기구로 주체만 이전되었을 뿐이다.

그들은 식민지에서 비누사용이 늘고 추장집에서 현대식 욕실이 갖추어져 있다고 하면서 위 생시설이 좋아졌다고 자축하였다. 자전거와 자동차가 굴러다니고 집이 개조되고 정원이 있고 울타리가 있는 집이 있다는 보고서를 내면서 개발 단계가 높아지고 있다고 자평하였다. 식민 화로 잃어버린 현지의 전통문화유산이 자동차와 현대식 욕실로 채색되기 시작한 것이다. 그리 고 국제사회는 개발협력이 순조롭게 진행되고 있다고 스스로 위안 삼았다. 오늘날 국제개발협 력의 평가 방법을 이미 제시한 것이다.

국제 연맹에 맡겨진 신성한 문명이라는 유산은 2차 대전 후 미국이 국제무대에 적극 개입하 면서 새로운 성격을 띠게 되었다. 2차 세계 대전 후 미국은 소련의 팽창을 억제하기 위한 외교 전략의 일환으로 개도국을 지원한다는 정책을 수립하였다. 트루만 대통령의 포인트 IV 프로그 램을 통하여 라틴아메리카에 지원해 온 기술 원조를 저개발지역(underdeveloped areas)으로 확대한다고 밝힘으로써 미국을 주축으로한 개발 원조의 시대가 열린 것이다. 무엇보다, 트루 만 대통령은 전세계를 개발국가와 저개발국가로 구분하고, 저개발국가를 미국이나 서구의 생 활 수준에 미치지 못하는 모든 나라라고 정의하였다. 그러면서, 저개발지역의 가난과 불행과 억압을 미국의 산업과 과학기술의 원조로 극복하도록 도와주어야 한다고 천명하였다. 아울러, 트루만 대통령은 포인트 IV를 통하여 미국은 다른 국가의 산업활동을 지원하고 생활수준을 향 상시킨다고 밝혔다. 이러한 계획은 과거의 제국주의와 달리 민주적이면서 공정한 개념에 기초 한다고 밝히고, 다른 국가들도 개발을 필요로 하는 지역에 자본을 투자하여 줄 것을 요망하였 다. 또한, 모든 국가는 UN 등 국제기구와 함께 저개발 지역의 개발이 배고픔과 불행, 절망에 서 벗어나도록 도와주어야 하며, 이러한 노력을 평화로운 풍요와 자유를 위한 범세계적 노력 이라고 평하였다. 특히, 트루만 대통령은 더 많은 생산(greater production)이 번영과 평화의 열쇠이며 이를 위하여 가장 뛰어난 미국의 현대과학과 기술에 대한 지식을 적용해야한다고 언 급하였다. 그러나, 실체는 식민제국시대의 저문명국을 고문명국가로 변형시켜야 한다는 논리 와 다름이 아니었다. 


\section{III. 아프리카의 인식체계}

\section{1. 헤겔과 아프리카17)}

아프리카의 인식체계는 긴 역사를 통하여 자생적이고 점진적으로 형성되었다기 보다는 유 럽의 아프리카에 대한 부정적 인식에 대응하면서 확립되어 왔다. 아프리카에 대한 인식이 부 정적이고 이미지가 좋지 않은 것은 무엇보다 헤겔의 아프리카에 대한 부정적 평가 때문이다. 헤겔은 아프리카 대륙을 밟은 적이 없다. 그는 레비 부륄(Lévy-Bruyl)등 인류학자의 저서나 선교사의 보고서를 통하여 아프리카를 알게 되었다. 헤겔은 그의 저서 정신현상학 (Phenomenology of Spirit)을 통하여 모든 현상의 본질은 절대 정신(Absolute Geist)이고, 인류의 역사는 이 절대 정신을 찾아가는 과정이라고 생각 하였다. 헤겔은 절대정신의 본질은 자유이며, 역사는 이성적인 자유를 실현해가는 과정이라고 정의하고, 이를 변증법으로 설명하 였다. 아울러, 헤겔은 논리학(Science of Logic)에서 현실과 역사의 과정을 존재(sein), 무 (nichts), 생성(werden)이라는 세가지 요소를 통하여 설명하였다.

헤겔은 최고의 자유는 개인이 사회 전체의 보편적이면서 이성적인 의지에 따라 행동할 때 나타난다고 전제하고, 인종을 예로들어 역사의 변증법과 발전과정을 설명하였다. 동양인은 오 직 군주만이 그가 원하는 바를 행하는 것 외에 아무것도 모르고, 그리스인과 로마인은 시민의 개념은 알았지만 이는 소수에 국한되었다고 보았다. 반면, 게르만 민족은 모두가 자유롭다고 생각했다. 동양이나 지중해 인접국은 발전과정을 겪고 있으며, 게르만족만이 거의 완전단계 있다는 의미다. 그러나, 아프리카인은 아예 변증법이 해당되지 않는다고 보았다. 아프리카에 는 이성이 없기 때문에 발전과정도 없고 그 때문에 역사가 없다고 본 것이다.

헤겔은 아프리카의 자연관도 진화와는 연관이 없다고 생각했다. 헤겔은 인간의 출발개념이 정신이라면 자연의 출발개념은 공간(raum)이라고 생각하고, 인간과 공간사이의 다양한 사물 의 존재를 자연으로 파악했다. 또한, 인간의 정신을 자유(Freiheit)의 영역으로, 자연을 필연 (Notwendigheit)의 영역으로 구분하고 자유와 필연사이에 변증법과정이 지속적으로 전개되는 것을 역사의 발전 과정으로 보았다. 따라서 자연도 인간의 정신과 함께 단계를 밟으며 발전한 다고 본 것이다. 반면, 아프리카인에게는 자연은 초월적 존재로서 정신을 의미하고, 인간이 오

17) MLdéwalé-Kodjo-Jacob Agossou, Hegel et la philosophie africaine, KARTHALA, 2005

Amady Aly Dieng, Hegal et l'Afrigue noire, Hegel était-il raciste, CODESRIA, 2006 
히려 공간이기 때문에 진화할 수도 발전할 수도 없다는 것이다. 한마디로 낙원시대의 천진한 상태에 남아 있다는 것이다. 이 때문에 헤겔은 아프리카를 이해하기위해서는 서구의 인식체계 를 버려야 한다고 생각한 것이다. ${ }^{18)}$

\section{2. 아프리카 지식층에 나타나는 인식체계}

헤겔의 아프리카에 대한 인식과 평가를 위에서 간략하게 살펴보았다. 물론, 헤겔뿐만 아니 라 헤르더(Gottfried Herder)나 볼테르 등도 아프리카인을 동물에 비유하면서 정신적으로 쇠 퇴(decedent)하고 저능한(imbécillité) 인종이라고 극언하였다. 연수공무원(토고)도 강의 중 비슷한 내용을 밝혔다. 연수공무원은 "독일인이 토고에 처음 왔을 때 흑인들의 언어는 인간과 원숭이 사이의 언어라고 하면서 독일의 고급문화를 가르쳐줄 가치조차 없는 인종”으로 평했다 고 말했다.

서구에 대한 아프리카의 반응은 대체로 3 분류로 나타났다. 첫 번째 반응은 서구의 인식을 부정하면서 아프리카 고유의 전통(과거)을 다시 회복하자는 의견이다. 세제르같은 문학도들이 다. 둘째로, 과거로의 회귀를 맹렬히 비난하면서 혁명 등을 통하여 미래를 지향하라는 세력이 다. 화농 같은 지식층이 이를 대변한다. 셋째로, 과거 지향과 미래지향간의 중간노선을 취하는 세력으로서, 이들은 현실에 중점을 두되 과거의 전통을 회복하여 미래를 지향하자는 세력이 다. 자본주의도 공산주의도 아닌 제 3 의 길을 모색해야 한다는 소위 집권 엘리트층이다. 콩고 의 모부투대통령, 가봉의 봉고대통령, 코트리브와르의 우푸에 브와니 대통령 등이 이에 해당 한다.

3 가지의 분류의 근원은 프랑스의 시인 세제르19)에서 비롯되었다. 세제르는 1939 년 고향으 로 돌아가며(Cahier d'un retour au pays natal)라는 저서를 통하여 네그리튀드(negritude) 와 돌아가다(retour)자는 두 가지 개념을 도입하였다. 이 두 가지 개념은 아프리카의 정체성을 수립하는데 결정적 역할을 하였다. 나아가, 이 두 가지 개념은 학문계뿐만 아니라 아프리카의 정치·경제·사회·문화 등 제 분야에서 아프리카의 인식 체계를 이해하는데 중요한 요인으로 작 용하여 왔다. 네그리튀드는 세제르가 흑인들의 존엄성과 개성(personhod) 그리고 인간성 (humanity)을 개념으로 나타내기 위하여 만들었다. 돌아가다는 역사적의 의미와 형이상학적

18) G.W.F. Hegel, La raison dans I'histoire, UGE Paris 10/18, 1965

19) Amié Césaire, Cahier d'un retour au pays natal (영어로는 Return to My Native Land로 번역됨), 1939 
의미를 내포하고 있다. 역사적인 의미에서 돌아가다는 아프리카의 역사와 아프리카 사람들의 인식 속으로 돌아가 아프리카의 존엄성과 개성을 되찾아야 한다는 의미다. 형이상학적 의미에 서 돌아가다는 서구 문화 중심의 인식체계에서 벗어나 소외되었던 아프리카의 정체성을 되찾고 이를 아프리카주의(Africanism)나 민족주의(nationalism)의 이념으로 승화시킨다는 의미다.

노예무역은 아프라카인들이 사회적으로나 인종적으로 결속(solidarity)을 다지는 계기를 만 들어 주었다. 때문에, 아프리카인들에게 결속은 오만함과 호전적인 서구중심의 문화에 대항하 는 힘이고 무기였다. 이런 의미에서, 돌아가다는 흑인들이 한데 뭉쳐 모두 함께하는 공동체로 집결하자는 이데올로기 내지 혁명적 의미를 내포하고 있다.

세네갈 셍고르(Senghor) 대통령도 아프리카의 문화와 정체성을 찾기 위하여 네그리뛰드라 는 말을 즐겨 사용하였다. 셍고르 대통령은 아프리카인들은 초자연적인 정신과 힘에 의존하여 그 속에서 감성적 위안을 찾고 느끼고 생동한다고 생각하였다. 그는 서구의 분석적 이성으로 는 인간의 감성을 읽지 못하고, 설정된 목표라는 객관적 표적만 지향하기 때문에 아프리카의 이성에 대한 서구의 이해는 충분치 못하다고 밝혔다. 셍고르 대통령은 아프리카인들은 나무나 돌, 인간이나 동물을 사회현상과 구분하지 않는다고 여긴다. ${ }^{20)}$. 아프리카인은 자연을 분석하 지 않고 눈먼 사람처럼 자연을 간직할 뿐이다. 자연을 손으로 만지고 느끼며, 곤충의 촉수처럼 자연을 더듬으며 자연을 이해하고 자연과 함께 살아간다. 아프리카인들은 자연과의 이러한 관 계를 음악이나 시나, 춤 등 민속, 전통의례, 속담 등으로 표현한다고 보았다. 아프리카의 지식 인들은 셍고르 대통령이 아프리카의 열등감을 치유하지 못하면서 아프리카는 이성도 없고 지 식도 없이 순수한 감성만 있는 것으로 평가하였다고 대통령을 비난하여 왔다. 그러나 백인 유 럽의 문명과 흑인 아프리카의 문명은 다를 수 밖에 없다고 밝히고, 그 이유를 규명코자 노력했 던 사실은 높이 평가받고 있다. 셍고르 대통령은 서구의 이성과 객관성은 인간이라는 주체와 자연이나 사물과 같은 객체를 인위적으로 구분하는 데 단지 이용되는 척도에 지나지 않기 때 문에 인간의 본질을 파악하는 데 제한적으로 작용할 뿐이라고 생각했다. 그는 아프리카의 인 간에 대한 이해는 생각뿐만 아니라 느끼는 것이기 때문에 아프리카의 인식 형태가 보다 총체 적인 것이라고 믿었다. ${ }^{21)}$

아프리카 지식층은 서구의 아프리카에 대한 부정적 인식이 서구의 자기중심적인 사고에서

20) William Van Orman Quine, Two dogmas of Empiricism, 1951

21) L'eopold Sédar Sengor, Négritude et Civilisation de I'Universel, Présence africaine. XLVI, 2e trimertre, 1963, De la Négritude. Psychologie du Négro-africain, Diogロne no 37, janvier-mars 1962, Eléments constitutifs d'une civilisation négro-aficaine, in Liberté I. Négritude et Humanisme, Seuil, 1964 
비롯되었다고 생각한다. 서구가 아프리카의 정신 수준이나 이성이 미발달된 수준(prelogical and precritical)이라는 인류학자들의 주장에 설득되어 아프리카의 언어에 내재된 철학적인 의미를 분석하려고 하지 않는다고 지적하였다. 서구는 아프리카의 인식체계에 대한 연구 자체 를 거부하였기 때문에, 아프리카 철학이 서구처럼 분석적이고 논리적임에도 불구하고 학문으 로서 취급을 받지 못하고 있다고 생각하여왔다. 즉, 서구가 아프리카에 대한 연구와 이해없이 선험적으로 아프리카의 철학은 비정상적인 전통의 형태라고 평가하였기 때문에 아프리카 철학 은 철학의 영역에 조차 들어서지 못하였다고 본 것이다.

미국의 철학자 퀸느(Quine)는 아프리카 철학의 이러한 문제점을 해결하는 실마리를 제공하 였다. 퀸느는 행동이나 말의 의미는 특수한 문화와 사회를 나타내는 존재론적이며 인식론적이 고 심미적인 위상을 지닌다고 주장하였다. 그는 비서구지역의 언어를 서구에서 일상적으로 사 용하는 언어로 번역하였을 경우, 번역된 언어는 현지인이 뜻하는 것을 제대로 나타내지 못한 다고 생각하였다. 일례로, 아프리카의 요루바(yoruba)22) 지방에서 사용하는 지식, 믿음, 주술 이라는 용어를 영어로 knowledge, belief, witchcraft로 번역하지만, 요루바 언어의 의미는 영어로 번역된 뜻과 다르다는 사실이다. 때문에, 영어권에서 보면 요루바 언어는 논리와 판단 력이 발달하지 못한 언어로 간주된다. 따라서, 아프리카의 철학도 당연히 논리와 판단력이 발 달하지 못한 것은 추론되기 때문에 보편적 철학으로 취급받지 못한다는 주장이다.

요루바 지역에서는 직접(firsthand)경험에서 나온 사실만이 지식이나 진실(truth)이다. 직 접 경험한 지식은 별도로 검증할 필요가 없이 그 자체가 당위성(justification)을 갖는다. 간접 (secondhand)경험한 것은 믿음(belief)으로 표현된다. 따라서, 영어권 사람이 요루바 지역사 람들이 직접 경험하지 않은 사실을 지식이라고 하면, 요루바 사람들은 영어권 사람을 순진하 고 무지한 사람으로 간주한다23).

특히 요루바 사회에서 의사전달은 주로 말(oral)에 의존하고 있기 때문에, 어떤 사람이 믿을 만 한 지식의 원천이 되기 위해서는 솔직하고, 남의 말에 경청하는 등 지켜야 할 도덕적 의무 (윤리)가 있다. 결과적으로, 믿을 만한 지식을 보유한 사람으로 알려지면 그 사람이 바로 본받 을 좋은 도덕률이 된다. 따라서, 특정의 도덕적 가치가 인식론적 덕(epistemological virtue) 으로 특정지어진다. 이런 맥락에서 요루바 지역에서 참으로 아름답다는 도덕적 의미에서 아름 다움을 뜻한다. 미(beauty)는 육체적, 외형적 현상을 의미하는 것이 아니라 내면적인 도덕성 을 의미한다. 이런 관점에서, 아프리카의 인식체계, 도덕관 및 심미안은 서구와 다르다.

22) 요루바로 불리는 서부아프리카 지역(나이지리아, 토고, 콩고 등)에서 약 2천8백만 인구가 요루바어를 사용 하고 있다.

23) Barry Hallen, A Short History of African Philosophy, pp.36-67 
나이지리아의 이바단대학의 소고로(Sogolo)철학교수도 아프리카 사람의 생활 형태는 유별 나기 때문에 서구철학으로는 도저히 이해할 수 없다고 밝혔다. 특히 소로고 교수는 이성에 의 한 논리전개는 문화적 요인의 영향을 받기 때문에, 특정문화에 바탕을 둔 논리가 서구의 논리 와 다르다고 해서 합리성이 결여된 것은 아니라고 지적하였다. 그는 아프리카의 정신구조가 서구와 차이는 없다고 보았다. 다만, 아프리카 사회와 서구사회는 서로 다른 형태의 생활양식 을 갖고 있기 때문에 아프리카인들의 현실에 대한 인식과 사물을 설명하는 방법은 서구와 다 를 수밖에 없다고 보았다24). 따라서, 아프리카인의 사고방식을 이해하기 위해서는 아프리카 고유의 논리와 합리성의 기준으로 분석해야 한다고 주장하였다. 한 예로, 아프리카 사회는 주 술과 정신세계로 충만된 세계인데 이를 서구기준의 과학적 합리성으로 아프리카 세계를 분석 하면 아프리카의 정신수준은 미발달된 것으로 나타날 수밖에 없다는 것이다. 소고로 교수는 아프리카의 정신구조를 이해하기 위해서 무엇보다 아프리카인들의 독특한 생활문화와 담론에 대한 깊은 이해와 통찰이 필요하다고 보았다. 콩고 연수공무원도 이를 have(소유하다) 동사를 통하여 설명했다. 아프리카에서 내가 소유하다(have)는 내가 혼자 가지는 것이 아니라 누구와 함께(with) 소유한다는 공동체적 의미를 갖고 있다고 설명하고, 이러한 의미는 아프리카의 공 동체를 이해하는데 도움이 된다고 밝혔다.

나이지리아의 아오로오대학의 매킨드(Makinde)교수는 서구의 분석적인 학문연구방법과 패 러다임이 세계를 독점하면서, 서구의 방법과 패러다임에 맞지 않는 사고방식이나 믿음 그리고 문화는 연구할 가치가 없다는 서구의 논리를 강하게 반박하였다. 매킨드 교수는 철학은 비평 적 논리뿐만 아니라 형이상학적인 사고로 접근해야 한다고 전제하고, 아프리카의 철학은 서구 의 논리적 접근과는 달리 형이상학을 강조한 방법으로 발전시켜야 한다고 주장하였다. 그는 점술(divination)은 과학적 방법에 근거하지는 않지만, 사회 현실을 이해하고 사회문제를 해 결하는데 과학보다는 더 유용할 수 있다고 보고, 아프리카의 전통의술과 철학을 연계시키면, 과학과 점술간의 융합을 시도하였다.

무딤베 철학교수는25) 인류학이든 철학이든 문학이든 모든 학문이 서구의 문화에 우선을 두 고 서구문화에 편중되어 있기 때문에, 아프리카의 초상(portrait)도 유럽의 문화에 비추어 나 타날 수 밖에 없다고 간파하였다. 아프리카 철학이 서구 철학의 연구방법을 답습하여 연구되 어왔기 때문에 아프리카 철학은 본연의 위치를 찾지 못하였다고 주장하였다. 즉, 무딤베는 아

24) Godwin Sogolo, Foundations of African Philosophy: A definitive Analysis of Conceptual Issues in African Thought, 1993

25) 무딤브 교수는 스탠포드대학에서 인류학 언어학 및 문학 교수로 재임한바 있고, 현재는 듀크대학에서 문학을 강의하고 있다. 
프리카의 학자들이 서구의 학문연구방법에 충실한 나머지 아프리카 고유의 지식을 제대로 파 악하지 못하고 있다고 비판하면서, 아프리카는 재발견되어야 한다고 주장하였다. 그는 아프리 카의 지식을 누시스(gnosis)라는 지식으로 정의하고, 아프리카의 신비한 지식이 외국어로 번 역됨으로써 그 의미가 왜곡되었다고 지적하였다26). 무딤베는 아프리카의 철학에 대한 연구가 서구 중심의 인류학자들에 의하여 추진되었고, 이들은 지적진화과정에서 볼 때 아프리카인들 은 낮은 수준에 있었다고 기록함으로써, 아프리카인들은 지금도 지적으로 낮은 것으로 인식되 고 있다고 지적하였다. 무딤베는 템펠(Tempel)의 저서인 반투철학(Bantu Philosophy)을 예 로들어, 아프리카인은 이미 심오한 세계관을 지니고 있었으나, 서구의 인류학자들은 이를 간 과하거나 오역하고 있다고 밝히고, 아프리카를 재조명하는 새로운 패러다임을 개발해야 한다 고 주장하였다. 그는 아프리카에게 합리적인 새로운 패러다임이 서구의 관점에서 보면 이국적 이고 괴상한(bizarre) 사고의 틀로 비추어질 수 있다고 밝혔다. 프린스톤 대학의 아피아(A. Appiah)교수와 훈톤지(P. Hountondji) 오하이오 대학 교수도 아프리카 지식인은 아프리카 고 유의 철학을 형성해야 한다고 주장하였다. 그들은 각 국가는 자신의 철학을 자신의 행동과 자 신의 생각을 표현하기 위해 자신의 방법으로 모색해야 한다고 주장하였다.

\section{3. 이성으로 진화한 지배계층과 신화 속에 갇힌 국민27)}

아프리카 속담에 나무는 가지로 절대 심지 않는다(On ne plante jamais un arbre par son branchage)라는 말이 있다. 가지로 뿌리를 내릴 수 없다는 뜻이다. 서구의 인식체계는 아프리 카에 뿌리내릴 수 없다는 의미다. 아프리카 지식층은 위에서 대략 살펴본 바와 같이 서구중심 에서 벗어나 아프리카 고유의 전통문화유산으로 아프리카 고유의 이성과 가치관을 수립하여 아프리카 역사를 아프리카가 직접 쓰고 아프리카 문화의 정체성을 되찾자고 주창하였다. 지배 계층도 전통문화유산을 되찾으면 아프리카는 과거의 영광을 되찾을 수 있다고 국민을 설득하 고 희망을 주어왔다.

26) V.Y. Mudimbe, The Invention of Africa: Gnosis, Philosophy and the Order of Knowledge, 1988 p.186 27) 이에 대한 이해를 위해서 다음 문헌이 도움된다.

- Tidiane DIAKITE, L'Afrique Malade D'Elle-même Karthala, 1986

- Patrich Chabal et Jean-Pascal Daloz, L'Afrique est partie ECONOMICA, 1999

- Jean-François Bayart, L'Etat en Afrique, Fayard, 2006

- Axelle Kabou, Et Si L'Afrique Refusent le Développement? L'Harmattan, 1991

- Présence Africaine, 165/166

- Kwasi Wiredu(ed), A Companion to African philosophy, Blackwell, 2004

- Mehran Kamrava, Politics and society in the Third World, routledge, 1993 
그러나, 아프리카 국민은 지배계층의 이방인이었고 이방인이다. 아프리카의 지배계층은 묘 한 역사적 배경을 갖고 있다. 아프리카 지배계층은 서구에 유학하거나 식민통치조직에 가담하 면서 식민통치국과 유대관계를 맺어왔다. 특히, 백인문화를 접하면서 꿈이 백인이 되는 것이 었다.

독립 후에 지배계층은 식민통치시대의 백인의 모든 행태를 모방하려고 애써왔다. 백인의 소 비 패턴 등 사회현상뿐만 아니라 행정 등 국가 운영 형태까지 답습하고 있다. 백인이 자기 국 민을 차별하고 억압하였듯이 지배계층은 백인이 되어 자국 국민을 착취하고 있다. 국가는 독 립하였다고 하지만 국민들 눈에는 진짜 백인(le blanc)에서 가짜 백인(le faux blanc)으로 바 뀌었을 뿐이다. 아프리카 국민들에게 대지는 먹을 양식과 품위있는 삶을 보장해주는 값진 자 산이고 유산이다. 그런데 식민통치국은 그 대지에서 아프리카 국민들을 체포하여 때리고 굶주 리게 하고 심지어 학살까지 했다. 아프리카 국민들은 독립하면 그 폭력이 대지에서 영원히 사 라질 것으로 믿어 왔다. 그 대지에 과거의 영광이 다시 오면 잘 살을 것으로 믿어왔다. ${ }^{28)}$

가짜 백인인 지배계층은 지난 반세기동안 진짜 백인 행세를 하며 국민을 제 3 의 길이라는 이상야릇한 길로 인도하여 왔다. 우선, 지배계층에게 개발은 생활의 수준을 개선하고 높이는 의미를 갖지 않는다. 개발은 과거의 비참했던 노예무역이나 식민화라는 의식에서 단지 벗어나 는 것이었다. 아프리카 대륙을 저개발국가로 인식하는 것은 아프리카의 문명을 이해하지 못한 때문이며, 발전에 편향된 지식층에 의하여 조작된 용어일 뿐이라고 일축한다. 지배층(특히 대 통령들)은 국민들에게 많은 신화를 만들어 주었다. 다음의 몇가지 예가 이상한 길을 이해하는 데 도움을 준다.

“과학과 기술이 아프리카의 전통유산과 인간성을 파괴시켰다. 따라서 과학과 기술을 악마시 해야한다. 경제 개발이나 산업화라는 비인간적인 활동은 백인들의 몫이고, 우리 아프리카는 초자연속에서 우주에 대하여 논해야 한다. 서구는 재고로 쌓여있는 생산품목을 전세계의 쏠리 다니떼(연대)를 위하여 시기 놓치기 전에 빨리 나누어 주어야 한다. 서구는 차가운 기계와 비 정한 숫자로 돈을 번 후, 그 돈을 따뜻한 남쪽에 위치한 아프리카에서 쓰고 있다. 서구가 꿈을 꾸는 곳이 바로 여기 아프리카 대륙이다. 부모가 자식을 해고하지 못하듯이, 기업도 직원을 해 고하면 안된다.”

아프리카 어린이도 다른 대륙의 어린이와 마찬가지로 창의적이고 호기심 많고 다이나믹하 28) Mabika Kalanda, La remise en question, Base de la colonisation mentale, Bruxelles, Remarques, 1967 
다. 그러나 학교를 마치면 경직되고 창의력을 잃는다. 신화의 효과다. 그래서 코트디부아르 우 푸에 부아니 대통령은 내가 이런 학교(자국)에 내 자식을 보내면 나는 정신나간 사람이라고 했 다. 신은 서구에 문자를 주고 아프리카에게는 말을 주었다고 한다.

\section{$\mathrm{IV}$. 인식체계의 차이가 개발협력에 주는 시사점}

\section{1. 서구의 일방적 우월적 접근}

공동체의 의식구조가 경제사회발전에 미치는 영향에 대하여 토론하던중, 베넹 연수공무원 이 "아프리카의 지식층들이 아프리카의 지적 수준이 서구보다 높고 문명도 서구보다 발달되었 다고 하는데, 아프리카는 왜 서구의 원조를 받아야 하나요” 라는 의문을 제기하였다. 이에 대 해 세네갈 공무원이 답했다. "원조는 지적수준이나 문명과 관계 없어요. 국제협약이 원조를 주 기로 정해놓았기 때문이예요.” 이 문답은 지난 수십년간의 개발원조에 대한 서구와 아프리카 간의 인식차이를 어느 정도 감지할 수 있다.

아리스토텔레스 이후 계몽주의 초기까지 인류사회와 인류의 지식은 자연의 자생적 역동성 (autodynamique)에 의하여 발전한다고 보았다. 경제적 풍요를 향한 인류의 자연적 역동성을 필연에 의하여 정해진 순서에 따라 발전(development)한다고 이해하였다. 발전은 선택이 아 니라 역사의 궁극적 목표요, 숙명이라는 새로운 패러다임으로 자리 잡게 된 것이다. 새로운 패 러다임에 따르면 인류는 끓임없이 문명과 풍요라는 역사의 궁극적 목표를 항하여 발전하는 것 은 선택이 아니라 필연에 의한 것이다. 또한, 문명과 풍요는 일직선 상에 놓여있고, 유럽이 가 장 높은 수준에 도달해 있기 때문에, 유럽은 식민지와 후진국을 도와 줄 책임이 있다는 것이 다. 유럽이 도와주면, 세계는 평등 속에 유토피아적 사회가 될 것이라고 보았다. 결과적으로 새로운 패러다임은 개발은 역사의 필연이며, 개발을 위해서 서구의 노선을 따라야 한다는 논 리를 정립하였다.

18세기 사회유기체적 진화론이 대세를 이루면서 고급문명을 전파한다는 숭고한 사명이 식 민제국주의로 탈바꿈하였다. 사회 유기체적 진화론자들은 다윈의 이론을 사회발전이론에 적극 활용하였다. 그들은 다윈의 진화론을 확대 해석하여 제국주의를 과학적으로 정당화하면서 강 력한 이데올로기로 내세웠다. 사회 유기체적 진화론자들은 흑인은 가장 미개한 사회에 있고, 
서양은 가장 우수한 문명에 도달했기 때문에 서양이 야만지역을 점령하여 높은 수준의 문명을 전파해야한다는 제국주의 내지는 식민주의의 논리를 정당화하였다. 1870년대 이후 우승열패 (優勝劣敗), 즉 우월한 인종은 이기고 열등한 인종은 사라진다는 자연의 법칙이 제국주의의 정 당성을 뒷받침하였다. 1897년 챔버린 수상은 영국의 아프리카 식민지화는 위대한 지배민족의 역량과 자질에 근거한 것이며, 이는 영국의 국가적 사명이라고 하였다. 일본의 개화사상가 후 쿠자와 유키치는 조선은 미개하기 때문에 일본이 무력(문명의 병사)을 사용해서라도 조선의 발전을 도와주어야 한다고 주장했다.

2차 대전 이후 미국과 UN이 국제무대에서 서구를 대체하면서 국제개발협력의 특성도 변하 였다. 신민제국시대의 고급문화와 고급문명이라는 담론이 물질적 풍요로 대중화되었다. 야만 과 문명이라는 구분과 식민국가와 피식민국가라는 이분법이 개발과 저개발로 표현이 바뀌었 다. 이러한 새로운 이분법은 UN헌장과 인권선언 등과 어우러지면서 과거의 중앙과 변방이라 는 종속관계에서 표면적이나마 평등한 수평적 관계로 변화시키는데 이바지하였다. 제국주의 시대의 중앙에 의한 주변부 착취에서 선진국과 후진국 간의 통합으로 바뀌었다. 선진국과 저 개발국가는 동일 수평선 상에 있기 때문에 저개발 국가는 선진국이 그어놓은 수평선을 따르면 언젠가는 자동적으로 선진국이 된다는 희망까지 주게 되었다. 희망이 이루어지도록 저개발국 의 빈곤, 불행과 절망을 선진국의 물질적 풍요에 대비시키고 저개발국이 무엇을 해야할 지를 구체적으로 제시해 주었다. 서구가 고대의 자연에서 중세의 신 중심으로 그리고 근대의 인간 중심에서 식민제국주의를 거쳐 현재 물질적 풍요로운 단계에 도달했으니 이 과정을 밟으라는 의미다. 문화적 삶의 주관적 표준을 GNP라는 물질적인 객관적 수치로 측정하고 교정하라는 것이다. 이성과 합리성이 생산성, 혁신, 경쟁으로 변모한 것이다.

이와 같은 서구의 인식체계의 변화를 살펴볼 때 서구의 국제개발협력에 대한 인식은 3 가지 로 요약될 수 있다. 우선, 서구를 따라야한다는 인식이다. 서구의 고급문화와 문명 수준에 도 달하기 위하여 서구가 걸어온 길을 단선적으로 답습해야 한다는 논리다. 다음으로, 가르쳐야 한다는 인식이다. 서구가 우월하니 서구는 문화와 문명을 가르치고 기술을 가르쳐주어야 한다 는 논리다. 끝으로, '준다'는 인식이다. 가르쳐 따르게 하려면 주어야 한다는 논리다. 대표적으 로 원조는 반드시 주는 것으로 되었다. 이에 대하여 아프리카는 이성과 합리성으로 특정 지어 지는 서구의 인식체계를 거부하고 자신들의 고유의 정체성을 수립하겠다고 나섰다. 아프리카 는 제 3 의 길을 추구한다고 표방하고 표면적으로는 서구의 '가르침'을 따르지 않겠다는 뜻을 국 민들에게 내세워왔다. '준다'는 국제규약에 규정된 약속으로 생각하고 으레 주는 것으로 알고 받는 것으로 여겨왔다. 따르지는 않지만 주는 것은 받겠다는 편안한 생각이다. 


\section{2. 아프리카의 인식구조}

독립 후 아프리카의 인식체계는 오땅띠씨떼(authenticité)29)와 네그리뛰드로 집약된다. 이 러한 아프리카의 인식체계는 서구처럼 수세기에 거쳐 점진적으로 변화하여 온 것이 아니라, 서구의 아프리카에 대한 부정적 인식에 대한 반동으로 나타났다. 즉, 서구의 이성과 합리성 그 리고 과학을 서구의 오만함으로 간주한다. 그리고 서구의 오만함에서 비롯된 편견과 왜곡을 시정하는데 초점을 맞추어왔다.

아프리카는 아프리카의 오땅띠씨떼를 되찾으면 부흥한다고 밝혀왔다. 오땅띠씨떼는 문화적 이고 철학적인 의미를 내포하고 있다. 오땅띠씨떼는 자신의 본질을 알고 인식하여 자신의 정 체성을 확립하는 의지를 뜻하는데, 서구가 이를 파괴하였기 때문에 아프리카는 발전할 수 없 다고 아프리카의 지도층 인사들은 주장하여왔다. 콩고의 모부투 대통령이나 가봉의 봉고 대통 령 등 아프리카의 지도자급 인사들이 오땅띠씨떼라는 말을 정치적 맥락에서 즐겨 사용하였다. 이들은 아프리카 고유의 힘과 자원으로 영화로웠던 과거에 가치를 재창조하고 단결 속에 조화 로운 사회를 건설해 가는 의지가 오땅띠씨데라고 국민에게 밝혔다.

오땅띠씨떼는 아프리카 개발의 방법과 진로를 인식론적으로 밝혀주는 매우 중요한 생활 철 학이다. 오땅띠씨떼 없이는 비젼이 없고, 역사 없는 비젼은 미래를 기약할 수 없다고 믿었다. 농부가 생산성을 높이기 위하여 분발하고 개발을 위해 분투하기 위해서는 미래에 대한 기대가 있어야 하는데 그 미래는 과거의 유산인 오땅띠씨떼에서 비롯된다고 보았다. 다른 국가의 과 거와 다른 국가의 기력으로는 발전 할 수 없다는 뜻이다. 따라서, 교육의 제일 목표도 오땅띠 씨떼에 대한 인식을 제고하여 아프리카의 진정한 (authentique) 뿌리를 되찾는 것이었다. 이 런 맥락에서, 아프리카 국가의 일부 대통령은 자국민이 선진국 유학이나 선진국의 생활용품 사용을 못마땅하게 생각하였다. ${ }^{30)}$

오땅띠씨떼는 아프리카의 문화정체성을 근간으로 한다. 아프리카의 수많은 부족, 언어, 풍 습, 지리환경 등을 감안 할 때 아프리카의 문화정체성을 특정 개념으로 일반화 하는 것은 쉽지 않고 바람직 하지도 않다. 그럼에도 불구하고, 아프리카에 관한 사료, 정치인의 담론, 지식인 의 논리 등을 종합적으로 고찰 해볼 때, 문화정체성의 주요요인으로 영화로웠다는 과거에 대

29) Authenticité와 정체성(Identité)은 서로 다른 의미를 내포하고 있으나 하이데거는 동일한 의미로 사용했다. 본고에서 는 본래의 의미에 충실하기 위해 편의상 원어 발음대로 표기하였다.

30) 그러나, 자신들은 선진국의 사치품까지 즐겨 사용하여 왔다. 엘리트 계층은 대부분 선진국에서 유학하였다. 
한 향수, 공동체를 위한 쏠리다리떼(solidarité)31), 자연과 우주와 인간과 조화, 그리고 심미 적 보다는 생활 예술 4가지로 집약할 수 있다. 특히, 이중에서 공동체를 위한 쏠리다리떼가 정 치, 경제, 사회, 문화 등 제반 분야에 영향을 주면서 아프리카의 인식 구조를 구축하는데 결정적 인 요인으로 작용하여 왔다. 이 때문에, 지금도 기회만 있으면 쏠리다리떼라는 단어가 등장한 다. 요약하면, 아프리카의 인식체계는 오땅띠씨떼, 쏠리다리떼, 네그리뛰드로 설명 될 수 있 고, 이러한 인식체계는 개발에 부정적 영향을 미쳐왔다.

우선, 네그리뛰드는 앞에서 살펴본 바와 같이 미래에 대한 비젼보다는 과거에로의 회귀를 중시하였다. 셍고르 대통령은 네그리뛰드를 문학적으로 승화시키는데 만족하였다. 화농은 네 그리뛰드를 아프리카의 인식체계를 바꾸는 혁명적 운동으로 발전시키려 했다. 그는 아프리카 가 현재 겪고 있는 소외와 정신착란은 식민주의 때문이며, 이를 극복하는 방법은 혁명이고 목 적은 자유라고 부르짖었다. 그는 민족문화의 네그리뛰드란 민속이나 애국심같은 추상적인 말 이 아니라 자신의 힘으로 자신의 존재를 창조시키는 행동이라고 믿었다. ${ }^{32)}$ 프랑스의 철학자 사르뜨르도 네그리뛰드는 서구의 인식체계에 대한 반명제(antithese)이며 이를 미래 가치로 발전(sythese)시켜야 한다고 생각하였다. 그러나 네그리뛰드는 정치적 담론이 되고 문학의 한 소절이 되면서 본래의 의미는 퇴색되고 서구에 대한 열등감을 오히려 증폭시켰다. 때문에, 아 프리카 사람들에게 네그리뛰드를 화두로 던지면 대부분 이맛살을 찌푸린다.

다음으로, 오땅띠씨떼는 서구에서 수입한 이데올로기를 거부하고 식민문화의 잔재에서 벗 어나 아프리카의 혼으로 서구에 대한 역등감을 극복하고 아프리카의 가치관을 세워 발전한다 는 이념이었다. 그러나, 아프리카 지도자들은 오땅띠씨떼를 실천하려는 의지보다는 정치적 담 론으로 활용하였다. 국민들에게는 오땅띠씨떼가 문화적 유산의 가치를 되살리고 잘 살게 하는 가치관이라고 설명하고, 자신의 독재 권력의 유지와 개인숭배를 합리화시키는 도구로 활용했 다. 이제 오땅띠씨떼는 신화로 남아가고 있다. ${ }^{33)}$

끝으로, 쏠리다리떼다. 쏠리다리떼는 오늘날 아프리카 뿐만아니라 개도국 전체의 정차·경제 사회현상을 나타내는 중요한 단어다. 쏠리데리떼는 제 3 세계가 제 3 의 노선을 추구하는 기본 개

31) 아프리카인에게 solidarité는 일반적인 연대, 결속 등보다 휠씬 강한 의미를 갖고 있다. 때문에 원음대로 표기하였다.

32) Franz, Fanon, Pour la révolution Africaine. Ccrits politiques, Paris, Faranपois Maspero, 1969, Peau noire, masques blancs, Seuil 1952

33) El Hadj Dmar Bongo, Réalités Gabonaises, Culture et développement, Multipress-Gabon, Mukulumanya Wa N'Gate, Authenticité: Mythe on idéologie in Authenticité et développement, Présence Africaine 1982. 
념이였다. 자본주의도 공산주의도 아닌 제 3 의 길을 개척하기 위한 일종의 이데올로기였다. 쏠 리데리떼는 1차적으로 식민제국주의에 대항하기 위한 피식민지의 자생적인 운동정신이었다. 제국주의의 표상인 자본주의를 배척한다는 의미를 내포하고 있다. 또한, 마르크스가 지적한 노동에 의한 인간의 소외(alienation)를 극복하는 대안으로 쏠리데리떼를 내세웠다. 마르크스 와 다른 점은 사적재산을 인정한 쏠리데리떼였다. 그리고 비밀결사 단체인 프리메이슨 (Freemason) ${ }^{34)}$ 도 개도국의 쏠리다리떼라는 공동체 정신에 크게 이바지 하였다. 쏠리데리떼 는 한마디로 개인의 삶에 우선하여 공동체가 있고 모든 사고와 행동이 공동체를 위해야 한다 는 이념이다.

쏠리데리떼라는 정신으로 집권층은 국민에게 물질적으로 지원하고 국민은 그 대가로 체제 의 합법성을 담보해주었다. 사회나 마을 차원에서 보면 대중은 공동체의 쏠리데리떼를 위하여 자신의 소득 중 30 40\%를 공동체에 내놓아야 한다. 남보다 뛰어나면 안 되고 뛰어난 사람을 칭찬해도 안 된다. 국가지도자는 어느 정도까지 달리다가 거꾸로 방향을 틀어 모두가 함께 결 승점에 도달하도록 해야 존경받는다. 사회계층간 빈부격차도 쏠리데리떼를 위해 필요하다. 지 배층은 이를 교묘히 활용하여 이권과 권력을 독점하여왔다. 이러한 쏠리데리떼는 자본주의의 원동력인 경쟁과 기업가 정신과 도저히 양립할 수 없다.

아프리카인들에게는 소유보다는 존재가 훨씬 가치가 있다. 때문에 존재론적 차원에서 공동 체가 최우선이다. 아프리카에 “가난도 형제와, 부(富)도 형제”와 함께 한다는 속담이 있다. 가 난이나 잘사는 것 모두가 개인이 아니라 공동체의 현상이다. 공동체와 가족을 떠난 부는 의미 가 없다. 아프리카의 공동체는 마르크스의 생산수단의 공유와 근본적으로 다르다. 아프리카의 공동체 정신은 현실에서의 경제적 사회적 유대 뿐만 아니라 신과 자연과 조상과 함께하는 의 식세계다. 마르크스의 하부구조가 없이 상부구조를 세우는 신화를 창조하고 있다. 이러한 인 식은 공동체에 국한된 것이 아니라 국가 나아가 아프리카 대륙 전체에 뿌리를 깊이 내려왔다.

지배계층은 쏠리데리떼를 정권유지의 수단으로 활용하여왔다. 국민들은 공동체 속에 진정 한 행복과 발전이 있다고 믿어왔다. 그들은 한국이 잘 사는데 왜 자살률이 높은지 이해하지 못 한다.

34) Axel Eric AUGE, Le recrutement des élites politiques en Afrique subsaharienne, L'Harmattan, 2005. 


\section{V. 맺는 말}

우리는 이성으로 진리를 판단한다고 믿어왔다. 판단의 옳고 그름을 떠나, 이성이라는 준거 의 틀은 제한적이다. 시몬(Simon)이 지적한대로 인간의 이성은 불완전하고 본질적인 것이 아 니라 제한적이며 절차적일 뿐이다. 타이프라이터의 QWERTY의 배열은 이성으로 보면 비합리 적이지만 그 배열은 오랫동안 우리를 합리적인 것으로 인식하게 작용하여왔다. 데카르트는 인 간은 비이성적인 자연을 인간의 이성으로 개조하여 합리적으로 만들 수 있다고 보았다. 그러 나 이성과 합리성으로 특정 지어진 서구가 아프리카에 고통을 주고 아프리카를 착취하였다. 전쟁으로 자신들까지 희생시켰다.

이성도 최고의 선을 지향하여 진화한다고 볼 때, 서구의 인식체계가 보편적일 수 없다. 서 구의 문화와 문명에서 비롯된 발전(progress)과 개발(developpement)이라는 개념도 서구중심 의 발상일 뿐이다. 사실 자본주의가 태동하기 이전에는 물질적인 이득과 이윤은 불경스런 악 마의 교리(doctrine of the evil)였다. 혁신과 효율과 경쟁은 사악한 반역적 개념이었다. 그러 나, 산엽혁명을 거치면서 인간은 정신적 풍요보다는 물질적 풍요를 중시하게 되었다. 그것이 모두가 거쳐야 할 정해진 노선이라고 믿어왔다.

착취와 소외에 시달린 아프리카대륙은 자본주의도 공산주의도 아닌 제 3 의 길을 표방하고 나 섰다. 제 3 의 길은 나(I)라는 개인이 주체가 되어 자율적인 자유를 찾아 가는 것이 아니라 우리 (we)가 하나되어 살기 좋은 공동체를 함께 만들어 가는 길이다. 그 길은 이윤을 극대화 하기 위한 경쟁이 아니라 못살아도 좋으니 함께 하자는 쏠리다리떼를 위한 길이다. 그 길은 이성과 합리성으로 진리를 찾겠다는 서구식의 길이 아니다. 그 길은 쏠리다리떼(연대)와 오땅띠씨떼 (정체성)으로 흑인의 정신(네그리뛰드)을 되찾아 과거의 영광된 전통유산을 찾아가는 길이다.

아프리카의 지도층과 지식층들은 아프리카 고유의 철학과 이념을 수립하여 진정한 독립을 달성하자고 외쳤다. 가나의 은쿠르마 대통령은 아프리카의 역사는 아프리카인이 써야 한다고 역설했다. Post-colonialism시대를 맞아 아프리카에 각인된 서구의 생각이나 징표 등을 없애 고, 서구의 담론도 아프리카의 정통성에 맞게 재해석해야 한다고 나섰다. 그러나 아직까지 결 과가 없다. 과거 식민통치국의 대통령 이름이 아프리카의 독립 광장의 이름으로 여전히 불려 지고 있다. 
나이지리아 오바사로 대통령, 음베키 남아공대통령, 와드 세네갈 대통령 등은 새천년개발목 표(MDG)를 아프리카 차원에서 이행하기 위하여 아프리카 개발을 위한 파트너쉽(NEPAD)을 주창하였다. 그들은 선정(good governance)은 선진국에게 투명성을 통한 효율성과 생산성 제 고를 의미한다면, 아프리카에게는 쏠리다리떼로 공동체의 결속을 굳게 다지는 뜻이라고 밝혔 다. 가봉의 봉고 대통령은 서구가 아프리카에 농업을 적극 장려하는 숨은 의도는 아프리카의 산업을 공동화시키는 데 있다고 국민들을 교육시켰다. 그리고 서구는 아프리카의 산업화를 시 기하고 있으며 아프리카가 산업화되면 다시 침략할 것이라고 천명하였다.

아프리카는 국제개발협력의 청사진인 파리선언을 자신의 인식체계로 해석하고 있다. 국제 사회는 국제개발협력의 효과가 나타나기를 기대하고 있다. 지난 반세기 동안 국제개발협력이 라는 말은 1960년대 경제성장 1970년대 분배와 인간의 기본 필요충족, 1980 년대 구조조정, 1990 년대 지속가능개발과 세계화 그리고 금세기 들어 새천년개발목표(MDG)로 말만 개발되어 왔다. 서구와 아프리카의 인식체계가 평행선을 달리고, 그 가운데 이상야릇한 제 3 의 길이 또 다른 평행선을 달리는 한 아프리카대륙에서 개발을 기대하는 것은 환상이다. 


\section{참고문헌}

Auguste Compte, Système de politique positive ou Traité de sociologie institutuant la religion de l'humanité, 1854.

Amady Aly Dieng, Hegal et l'Afrigue noire, Hegel était-il raciste, CODESRIA, 2006

Amié Césaire, Cahier d'un retour au pays natal 1939

Axel Eric AUGE, Le recrutement des élites politiques en Afrique subsaharienne, L'Harmattan, 2005 .

El Hadj Dmar Bongo, Réalités Gabonaises, Culture et développement, Multipress-Gabon, Mukulumanya Wa N'Gate, Authenticité: Mythe on idéologie in Authenticité et développement, Présence Africaine 1982.

Godwin Sogolo, Foundations of African Philosophy: A definitive Analysis of Conceptual Issues in African Thought, 1993

G.W.F. Hegel, La raison dans l'histoire, UGE Paris 10/18, 1965

Herbert Spencer, The Principles of Sociology vol.2, 1914

Herbert Spencer, A Theory of Population, Deduced from the General Law of Animal Fertility, The Development Hypothesis, 1852.

Jean-Baptise Say, Cours complet d'économie politique pratique, Bruxelles, Société typographe belge, 1843.

Jean-Jaques Rousseau, Du contrat social. Discours sur les sciences et les arts. Discours sur l'origne de l'inégalité parmi les hommes, Paris, Union générale d'éditions, 1973.

Jean-Marc Ela, Les Cultures Africaines Dans le champ de la Rationalité Scientifique, Livre II, L'Harmattan, 2007

Mabika Kalanda, La remise en question, Base de la colonisation mentale, Bruxelles, Remarques, 1967

Mèdéwalé-Kodjo-Jacob Agossou, Hegel et la philosophie africaine, KARTHALA, 2005

Paul Leroy-Beaulieu, De la Colonisation chez les peuples modernes, 1874.

William Van Orman Quine, Two dogmas of Empiricism, 1951 